\title{
Criminal Victimization and Comorbid Substance Use and Psychiatric Disorders in the United States: Results from the NESARC
}

\author{
MICHAEL G. VAUGHN, PhD, QIANG FU, MD, PhD, MATT DELISI, PhD, \\ KEVIN M. BEAVER, PHD, BRIAN E. PERRON, PHD, AND MATTHEW O. HOWARD, PHD
}

\begin{abstract}
PURPOSE: Criminal victimization produces enormous personal and societal costs, yet few investigations have systematically examined substance use and psychiatric disorders of crime victims. Our objectives were to (i) examine the prevalence and patterns of criminal victimization in the United States and (ii) their associations with specific substance use disorders, prevalent psychiatric conditions, and violent and nonviolent antisocial behaviors in controlled multivariate analyses.

METHODS: Data were derived from the National Epidemiologic Survey on Alcohol and Related Conditions, a nationally representative sample of US residents 18 years of age and older $(N=43,093)$. Interviews conducted between 2001 and 2002 included measures of past-year criminal victimization and Diagnostic and Statistical Manual of Mental Disorders, IV mood, anxiety, substance use, and personality disorders.

RESULTS: More than 1-in-25 adults in the United States (4.1\%) reported past-year criminal victimization. Respondents who reported lower levels of income, lived in urban areas, and were separated or divorced were at significantly heightened risk for criminal victimization. Persons reporting various forms of violent and nonviolent antisocial behavior also were more likely to be victims of crime. In controlled multivariate analyses, crime victims evidenced significantly increased rates of alcohol, cocaine, and opioid use disorders. Paranoid personality disorder, major depressive disorder, and a family history of antisocial behavior were also significantly associated with past-year criminal victimization.

CONCLUSIONS: Criminal victimization is prevalent in the United States and associated with significant psychiatric comorbidities and behavioral dysfunction. Poor, unmarried persons living in urban areas who have family histories of antisocial conduct and personal histories of specific substance use and psychiatric disorders are at substantially elevated risk for criminal victimization.

Ann Epidemiol 2010;20:281-288. (c) 2010 Elsevier Inc. All rights reserved.
\end{abstract}

KEY WORDS: Crime, Criminal Victimization, Mental Health and Victimization, Substance Abuse, Victimization.

\section{INTRODUCTION}

Criminal victimization has a profound effect on mental and physical health, and its costs to society are extensive (1-5). Although national victimization surveys differ in estimates of past-year prevalence rates (6), results indicate that millions of Americans in all age groups experience one or more lifetime victimization episodes. By using nationally

From the School of Social Work and Department of Community Health, Division of Epidemiology (M.G.V.), and Department of Biostatistics (Q.F.), School of Public Health, Saint Louis University, St. Louis, MO; Criminology and Criminal Justice Studies, Department of Sociology, Iowa State University, Ames, IA (M.D.); College of Criminology and Criminal Justice, Florida State University, Tallahassee, FL (K.M.B.); School of Social Work, University of Michigan, Ann Arbor, MI (B.E.P.); and School of Social Work, University of North Carolina, Chapel Hill, NC (M.O.H.).

Address correspondence to: Michael G. Vaughn, Tegeler Hall, 3550 Lindell Boulevard, St. Louis, MO 63103. Tel.: 314-977-2718; Fax: 314-977-2731. E-mail: mvaughn9@slu.edu.

NESARC was funded by the National Institute on Alcohol Abuse and Alcoholism with additional support provided by the National Institute on Drug Abuse. The authors are grateful for support from NIH grants: DA021405 (Dr. Howard) and K07CA104119 (Dr. Fu).

Received June 4, 2009; accepted November 25, 2009. representative data from the Injury Control and Risk Survey (ICARIS-2), administered in 2001 to 2003, Simon et al. (7) found that $5.4 \%$ of the US adult population and $6.9 \%$ of persons in the 25- to 34-year age range experienced at least one violent victimization episode in the previous year. Importantly, this figure exceeds prevalence rates found from the National Criminal Victimization Survey (NCVS), which found that $3.4 \%$ of persons in the 25 - to 34-year age range experienced a robbery victimization and $1.2 \%$ experienced a rape/sexual assault victimization in 2007 (8). The disparities between these studies are largely the result of methodology, with the NCVS emphasizing criminal events and ICARIS-2 capturing victimization events not thought of necessarily as crimes. Weaknesses of these national surveys are the lack of extensive data on mental health and substance use disorders.

The authors of previous research $(9,10)$ suggest that individuals with mental health disorders are at heightened risk for violent victimization. Overall, rates of victimization are greater among persons with mental health disorders than in the general population. In a recent systematic review, Maniglio (11) synthesized nine studies comprising 


\section{Selected Abbreviations and Acronyms}

ICARIS-2 = Injury Control and Risk Survey

NCVS $=$ National Criminal Victimization Survey

NESARC $=$ Epidemiologic Survey on Alcohol and Related Conditions DSM $=$ Diagnostic and Statistical Manual of Mental Disorders

$\mathrm{OR}=$ odds ratio

$95 \% \mathrm{CI}=95 \%$ confidence interval

more than 5000 participants and found that the prevalence of victimization episodes experienced by persons with severe mental health disorders ranged from $4.3 \%$ to $35 \%$ across studies. Six of nine studies found rates of victimization greater than $10 \%$. Variables most associated with victimization across studies were alcohol and drug use, prior criminality, and psychiatric symptom severity. Another recent systematic review (12) examining studies published since 1990 found rates as high as 44\% (13); only three studies examined victimization and perpetration in the same sample, finding greater levels of victimization than perpetration. Clearly, the research literature is composed of far more studies of perpetration of violence by persons with mental health disorders, thereby obscuring their involvement as victims of violence.

Studies of the drugs/alcohol-victimization nexus suggest a close relationship between substance use (predominately alcohol) and risk for criminal victimization. Buss et al. (14) found that nearly $70 \%$ of assault victims seeking medical treatment screened positive for alcohol or illicit drug use. Studies have indicated that substance use is more prevalent among crime victims compared with nonvictims $(2,6)$ and heightens risk for further victimization (15-18). This finding is particularly of concern given the interrelationship between substances of abuse and victimization risk. Ramos-Lira et al (19) found that exposure to substances such as marijuana, cocaine, and inhalants increased risk for violent victimization. Much less attention has been devoted to evaluating associations of comorbid substance use and mental health disorders to criminal victimization. One of few such studies (20) found that individuals with comorbid substance use and mental health disorders experienced greater criminal victimization than individuals with either a mental health or substance use disorder alone. Unfortunately, these conclusions were based on small, nonrepresentative samples.

\section{Study Purpose}

In the present study, we used data from the National Epidemiologic Survey on Alcohol and Related Conditions to (i) examine the prevalence and patterns of criminal victimization across sociodemographic categories, (ii) assess the associations between past year criminal victimization and a range of antisocial behaviors, and (iii) estimate the strength of the associations between substance use disorders, specifically alcohol abuse/dependence, marijuana abuse/ dependence, nicotine dependence, and illicit substance use disorders (i.e., opioid, sedative, stimulant, tranquilizer, cocaine, and hallucinogens) in multivariate analyses while controlling for sociodemographic characteristics, personality disorders, and psychiatric diagnoses. Because their association with risky settings and/or psychologically disinhibiting effects, we hypothesize that alcohol abuse/dependence and the abuse/dependence on marijuana, cocaine, stimulants, opioids, and heroin will significantly increase the likelihood of experiencing a criminal victimization even while controlling for aforementioned mental health and psychiatric diagnoses and demographic variables.

\section{MATERIALS AND METHODS}

\section{Participants}

Study findings are based on data from the 2001 to 2002 National Epidemiologic Survey on Alcohol and Related Conditions (NESARC). NESARC is a nationally representative sample of 43,093 noninstitutionalized US residents aged 18 years and older (21). To be reflective of the general population, the survey gathered information on alcohol use and comorbid psychiatric disorders from individuals living in households in all 50 states and the District of Columbia. NESARC used a three-stage cluster sampling design, oversampling young adult, Hispanic, and African-American subjects in the interest of obtaining reliable statistical estimation in these subpopulations and to ensure appropriate representation of racial/ethnic subgroups, with an overall response rate of $81 \%$. Data were weighted at the individual and household levels to adjust for oversampling and nonresponse on demographic variables (i.e., age, race/ethnicity, sex, region, and place of residence). Data also were adjusted to be representative (on the basis of region, age, race, and ethnicity) of the US adult population as assessed during the 2000 Census. Study participants provided fully informed consent. The U.S. Census Bureau and the U.S. Office of Management and Budget approved the research protocol and informed consent procedures.

\section{Diagnostic Assessment and Sociodemographic Measures}

Data were collected through face-to-face interviews conducted by US Census workers trained by the National Institute on Alcohol and Alcoholism and U.S. Census Bureau. Interviewers administered the Alcohol Use Disorder and Associated Disabilities Interview Schedule-Diagnostic and Statistical Manual of Mental Disorders (DSM)-IV version, which has been shown to have good-to-excellent reliability 
in assessing alcohol and drug use in the general population $(22,23)$.

Information regarding past-year criminal victimization was determined on the basis of a single item embedded in the medical conditions interview module. All NESARC participants were asked the following question: "How many times were you personally a victim of a crime in the last 12 months?" Data did not allow for distinguishing whether this victimization was violent or nonviolent in nature. Analysis of the distributional properties of this item showed that there was a truncated distribution, with the vast majority of respondents answering zero $(N=40,237)$, and of those individuals responding yes to experiencing a criminal victimization, most answered once or twice $(N=1,779)$. Only a few respondents answered more than twice. Because of low power we therefore coded this past-year criminal victimization as a dichotomous response $(0=$ no, $1=$ yes $)$.

Several substance use disorders were assessed in NESARC. We used lifetime alcohol (alcohol abuse/dependence) and drug (abuse/dependence on heroin, hallucinogens, cocaine/crack, marijuana, stimulants, painkillers, tranquilizers, and sedatives) use disorders, and nicotine dependence. In addition, numerous psychiatric disorders were examined, including pathological gambling, and lifetime DSM-IV mood (major depression, dysthymia, and mania/hypomania) and anxiety (social phobia, generalized anxiety disorder, panic disorder, and specific phobia) disorders. Consistent with previous research $(24,25)$, personality disorder diagnoses reflected long-standing impairments, characteristic patterns of behavior, and exclusion of cases in which substance use intoxication or withdrawal, other medication use, or physical illnesses could have affected behavior. Disorders assessed included antisocial, avoidant, dependent, obsessive-compulsive, paranoid, schizoid, and histrionic personality disorders. Family history of antisocial behavior on the basis of any parental or sibling history of antisocial behavior also was assessed. Response categories for region of residence in United States, urbanicity, race/ethnicity, sex, age, marital status, educational background, unemployment status, and individual and family income are listed in Table 1.

\section{Statistical Analyses}

Weighted prevalence estimates and standard errors were computed by the use of SUDAAN Version 9.0 (26). This system implements a Taylor series linearization to adjust standard errors of estimates for complex survey sampling design effects including clustered data. Multivariate logistic regression analyses were conducted with simultaneous entry of previously described sociodemographic covariates, substance use disorders and psychiatric variables. Adjusted odds ratios (ORs) and 95\% confidence intervals (95\% $\mathrm{CIs}$ ) are presented to reflect association strength and significance. Adjusted ORs were considered significant only if associated CIs did not include the value 1.0.

\section{RESULTS}

\section{Sociodemographic Characteristics}

Approximately $4.1 \%$ of US adults reported past-year criminal victimization. The prevalence of past-year criminal victimization in the US population was $4.1 \%$. Table 1 provides comparisons of persons with and without a history of past-year criminal victimization across NESARC sociodemographic characteristics. Unadjusted analyses revealed that persons reporting a past-year criminal victimization were less likely to be age 35 and older and more likely to be between the ages of 18 and 34. Individuals reporting lower levels of annual income were more likely to be victimized compared with persons earning $\$ 70,000$ or more annually. With respect to marital status, those who were widowed/separated/divorced were 53\% more likely to report a criminal victimization compared to married or cohabitating persons. Spatially, respondents residing in urban environments (i.e., central city) were $31 \%$ more likely to report a criminal victimization than persons living in rural/suburban environments and those living in the Northeast (OR, 0.71; 95\% CI, 0.52-0.98) and Midwest (OR, 0.74; 95\% CI, 0.56-0.96) were significantly less likely than persons living in the West to report an episode of criminal victimization. There were no significant differences with respect to gender, race, and education.

\section{Victimization and Associated Antisocial Behaviors}

Table 2 displays results for the proportion of persons who reported an antisocial behavior who were victims and nonvictims. Among those respondents who endorsed an antisocial behavior, past-year crime victims reported engaging in significantly more antisocial behaviors than their nonvictimized counterparts. The largest ORs among violent behaviors between victimized and nonvictimized respondents were for robbing/mugging someone (OR, 4.49; 95\% CI, 2.3-8.28), forcing someone to have sex (OR, 3.86; 95\% CI, 1.41-10.59), and use of a weapon in a fight (OR, 3.38; CI, 2.61-4.38). With respect to nonviolent behaviors, the strongest effects were found for "scamming or conning" someone for money (OR, 3.61; 95\% CI, 2.61-4.99), use of an alias (OR, 3.10; 95\% CI, 2.33-4.10), and having no regular place to live (OR, 3.14; 95\% CI, 2.40-4.11). Conversely, the weakest effects found were for getting three or more traffic tickets (OR, 1.27; 95\% CI, 1.05-1.54). 


\section{Multivariate Logistic Regression Analysis Examining Associations between Victimization and Substance Use and Psychiatric Comorbidity}

Table 3 presents the prevalence of substance use and psychiatric disorders for persons reporting and not reporting a past-year criminal victimization. ORs were adjusted for sociodemographic factors (i.e., race, sex, education, marital status, age, income, region, and urbanicity) and previously described lifetime DSM-IV psychiatric disorders. The most prevalent substance use and psychiatric disorders among persons with a history of victimization were any past year alcohol use disorder (16.55\%; 95\% CI, 14.25\%-19.13\%) and nicotine dependence $(22.19 \%$; 95\% CI, 19.39\%$25.28 \%$ ). Although not classified as a disorder, having a family history of antisocial behavior was prevalent among victimized persons (37.31\%; 95\% CI, 33.58-41.21). Following adjustments, significant associations were found for major depressive disorder (OR, 1.27; 95\% CI, 1.01$1.60)$, panic disorder (OR, 1.42; 95\% CI, 1.01-1.99), any alcohol use disorder (OR, 1.35; 95\% CI, 1.10-1.65), nicotine dependence (OR, 1.25; 95\% CI, 1.04-1.49), opioid use disorder (OR, 2.56; 95\% CI, 1.18-5.56), cocaine use disorder (OR, 3.84; 95\% CI, 1.83-8.08), paranoid personality disorder (OR, 1.38; 95\% CI, 1.08-1.75), and family history of antisocial behavior (OR, 1.36; 95\% CI, 1.13-1.62).

\section{DISCUSSION}

To our knowledge, this is the largest national epidemiological study examining the associations between criminal

TABLE 1. Sociodemographic characteristics of NESARC respondents with and without a past 12-month criminal victimization

\begin{tabular}{|c|c|c|c|}
\hline Characteristic & Nonvictim $(n=40,237) \% \mathrm{CI}$ & Victim $(n=1,779) \% \mathrm{CI}$ & OR $(95 \% \mathrm{CI})$ \\
\hline \multicolumn{4}{|l|}{ Sex } \\
\hline Men & $47.77(47.24-48.48)$ & $50.73(46.86-54.58)$ & $1.10(0.98-1.25)$ \\
\hline Women & $52.23(51.61-52.86)$ & $49.27(45.42-53.14)$ & 1.00 \\
\hline \multicolumn{4}{|l|}{ Race } \\
\hline Hispanic & $11.51(9.28-14.20)$ & $11.62(8.66-15.41)$ & $0.97(0.80-1.18)$ \\
\hline Asian/Alaska/Indian & $4.43(3.46-5.64)$ & $2.90(1.80-4.63)$ & $0.92(0.60-1.42)$ \\
\hline Native American & $2.09(1.80-2.43)$ & $2.33(1.14-4.70)$ & $1.00(0.61-1.65)$ \\
\hline African American & $10.93(9.72-12.26)$ & $13.30(10.59-16.57)$ & $0.98(0.81-1.19)$ \\
\hline White & $71.04(67.73-74.14)$ & $69.86(65.51-73.87)$ & 1.00 \\
\hline \multicolumn{4}{|l|}{ Nativity } \\
\hline Born in the US & $85.34(82.06-88.10)$ & $89.39(86.19-91.91)$ & $1.22(0.98-1.51)$ \\
\hline Born in a foreign country & $14.66(11.90-17.94)$ & $10.61(8.09-13.81)$ & 1.00 \\
\hline \multicolumn{4}{|l|}{ Age, years } \\
\hline $65+$ & $16.51(15.86-17.19)$ & $7.29(5.61-9.42)$ & $0.42(0.34-0.52)$ \\
\hline $50-64$ & $21.35(20.82-21.90)$ & $10.53(8.65-12.76)$ & $0.50(0.41-0.61)$ \\
\hline $35-49$ & $30.98(30.34-31.63)$ & $34.94(31.37-38.70)$ & $0.83(0.72-0.96)$ \\
\hline $18-34$ & $31.16(30.27-32.05)$ & $47.23(43.34-51.16)$ & 1.00 \\
\hline \multicolumn{4}{|l|}{ Education } \\
\hline Less than high school & $15.53(14.58-16.53)$ & $13.67(10.82-17.13)$ & $0.97(0.81-1.18)$ \\
\hline High school graduate & $29.39(28.26-30.54)$ & $24.32(21.40-27.49)$ & $0.89(0.77-1.02)$ \\
\hline Some college or higher & $55.12(53.86-56.38)$ & $62.01(58.15-65.73)$ & 1.00 \\
\hline \multicolumn{4}{|l|}{ Income } \\
\hline $0-19,999$ & $23.23(22.29-24.20)$ & $27.07(23.60-30.85)$ & $1.55(1.25-1.91)$ \\
\hline $20,000-34,999$ & $20.03(19.37-20.71)$ & $21.07(18.26-24.17)$ & $1.43(1.18-1.73)$ \\
\hline $35,000-69,999$ & $32.27(31.61-32.94)$ & $32.49(29.17-36.00)$ & $1.25(1.06-1.48)$ \\
\hline $70,000+$ & $24.46(23.07-25.91)$ & $19.37(16.51-22.60)$ & 1.00 \\
\hline \multicolumn{4}{|l|}{ Marital status } \\
\hline Never married & $20.36(19.42-21.34)$ & $31.70(28.26-35.36)$ & $1.14(0.97-1.33)$ \\
\hline Widowed/separated/divorced & $17.20(16.74-17.67)$ & $20.57(17.84-23.59)$ & $1.53(1.28-1.83)$ \\
\hline Married/cohabitating & $62.43(61.48-63.38)$ & $47.73(43.51-51.99)$ & 1.00 \\
\hline \multicolumn{4}{|l|}{ Urbanicity } \\
\hline Central city & $29.17(24.97-33.74)$ & $38.40(33.24-43.85)$ & $1.31(1.13-1.51)$ \\
\hline Rural/suburban & $70.83(66.26-75.03)$ & $61.60(56.15-66.76)$ & 1.00 \\
\hline \multicolumn{4}{|l|}{ Region } \\
\hline Northeast & $19.83(13.86-27.56)$ & $16.57(11.27-23.69)$ & $0.71(0.52-0.98)$ \\
\hline Midwest & $23.30(17.53-30.27)$ & $21.88(15.59-29.82)$ & $0.74(0.56-0.96)$ \\
\hline South & $35.01(28.86-41.70)$ & $35.01(27.24-43.66)$ & $0.81(0.62-1.05)$ \\
\hline West & $21.86(15.71-29.57)$ & $26.55(18.31-36.82)$ & 1.00 \\
\hline
\end{tabular}

$95 \% \mathrm{CI}=95 \%$ confidence interval; OR $=$ odds ratio.

OR values in bold are statistically significant. 
TABLE 2. Past 12-month criminal victimization among adults endorsing a particular antisocial behavior

\begin{tabular}{|c|c|c|c|}
\hline Behavior & $\begin{array}{c}\text { Nonvictims }(n=39,998) \\
\% \%(95 \% \mathrm{CI})\end{array}$ & $\begin{array}{l}\text { Victims }(n=1,966) \\
\quad \%(95 \% \mathrm{CI})\end{array}$ & OR $(95 \% \mathrm{CI})$ \\
\hline \multicolumn{4}{|l|}{ Violent } \\
\hline Bullied people & $3.84(3.52-4.18)$ & $7.44(6.29-8.79)$ & $2.02(1.67-2.44)$ \\
\hline Set a fire on purpose & $3.99(3.69-4.32)$ & $9.82(6.65-14.25)$ & $2.62(1.75-3.92)$ \\
\hline Do things that could have easily hurt you/others & $3.81(3.50-4.15)$ & $5.59(4.84-6.44)$ & $1.49(1.28-1.74)$ \\
\hline Hurt an animal on purpose & $4.00(3.69-4.34)$ & $7.39(5.39-10.04)$ & $1.91(1.37-2.66)$ \\
\hline Destroy others' property & $3.87(3.56-4.20)$ & $8.93(7.14-11.12)$ & $2.44(1.91-3.11)$ \\
\hline Force someone to have sex & $4.05(3.74-4.39)$ & $14.02(5.60-30.96)$ & $3.86(1.41-10.59)$ \\
\hline Get into lots of fights that you started & $3.94(3.63-4.28)$ & $8.36(6.63-10.48)$ & $2.22(1.73-2.86)$ \\
\hline $\begin{array}{l}\text { Get into a fight that came to swapping blows with } \\
\text { Husband/Wife or boyfriend/Girlfriend }\end{array}$ & $3.69(3.37-4.03)$ & $9.39(8.14-10.82)$ & $2.71(2.28-3.22)$ \\
\hline Use a weapon in a fight & $3.88(3.57-4.21)$ & $10.85(8.63-13.55)$ & $3.02(2.35-3.87)$ \\
\hline Hit someone so hard that you injure them & $3.74(3.44-4.07)$ & $8.90(7.32-10.78)$ & $2.51(2.03-3.11)$ \\
\hline Harass/threaten/blackmail someone & $3.92(3.61-4.26)$ & $12.12(9.70-15.02)$ & $3.38(2.61-4.38)$ \\
\hline Hurt another person on purpose & $3.84(3.53-4.18)$ & $8.28(6.94-9.85)$ & $2.26(1.87-2.73)$ \\
\hline \multicolumn{4}{|l|}{ Nonviolent } \\
\hline Cut class and leave without permission & $3.49(3.18-3.84)$ & $6.08(5.43-6.80)$ & $1.79(1.56-2.05)$ \\
\hline Stay out late at night & $3.63(3.32-3.96)$ & $5.31(4.69-6.01)$ & $1.49(1.30-1.71)$ \\
\hline Run away from home & $3.79(3.49-4.12)$ & $8.75(7.35-10.39)$ & $2.43(2.00-2.95)$ \\
\hline Be absent from work/ school a lot & $3.69(3.39-4.02)$ & $9.04(7.60-10.71)$ & $2.59(2.13-3.15)$ \\
\hline Quit a job without knowing where to find another & $3.67(3.35-4.01)$ & $7.02(6.16-8.00)$ & $1.98(1.70-2.32)$ \\
\hline Quit a school program without knowing what to do next & $3.98(3.66-4.31)$ & $6.02(4.79-7.54)$ & $1.55(1.22-1.96)$ \\
\hline Travel around more than 1 month without plans & $3.86(3.55-4.20)$ & $9.63(7.75-11.92)$ & $2.65(2.08-3.39)$ \\
\hline Have no regular place to live at least 1 month & $3.86(3.55-4.20)$ & $11.19(8.84-14.08)$ & $3.14(2.40-4.11)$ \\
\hline Live with others at least 1 month & $3.75(3.43-4.11)$ & $6.51(5.69-7.45)$ & $1.79(1.52-2.10)$ \\
\hline Lie a lot & $3.82(3.51-4.16)$ & $8.23(6.96-9.71)$ & $2.26(1.86-2.74)$ \\
\hline Use a false or made up name/ alias & $3.90(3.60-4.23)$ & $11.19(8.59-14.45)$ & $3.10(2.33-4.12)$ \\
\hline Scam/con someone for money & $3.93(3.62-4.26)$ & $12.86(9.66-16.91)$ & $3.61(2.61-4.99)$ \\
\hline Get three or more traffic tickets for reckless driving/causing accidents & $3.97(3.65-4.33)$ & $5.01(4.22-5.94)$ & $1.27(1.05-1.54)$ \\
\hline Have a driver's license suspended/revoked & $3.79(3.48-4.13)$ & $7.29(6.15-8.63)$ & $2.00(91.65-2.42)$ \\
\hline Fail to pay off your debts & $3.84(3.54-4.17)$ & $9.05(7.31-11.16)$ & $2.49(1.97-3.14)$ \\
\hline Steal anything from others & $3.83(3.53-4.15)$ & $6.42(5.36-7.67)$ & $1.72(1.43-2.07)$ \\
\hline Forge someone's signature & $3.94(3.63-4.28)$ & $9.65(7.52-12.29)$ & $2.60(1.97-3.44)$ \\
\hline Shoplift & $3.72(3.44-4.03)$ & $6.73(5.64-8.01)$ & $1.87(1.56-2.23)$ \\
\hline Rob/mug someone or snatch a purse & $4.03(3.71-4.37)$ & $15.85(9.27-25.76)$ & $4.49(2.43-8.28)$ \\
\hline Make money illegally & $3.89(3.59-4.21)$ & $10.30(7.90-13.33)$ & $2.84(2.14-3.77)$ \\
\hline Do something you could have been arrested for & $3.60(3.31-3.91)$ & $6.66(5.82-7.61)$ & $1.91(1.66-2.20)$ \\
\hline
\end{tabular}

$95 \% \mathrm{CI}=95 \%$ confidence interval; OR $=$ odds ratio.

OR values in bold are statistically significant.

victimization, substance use and psychiatric disorders and antisocial behavior among residents in the United States. The prevalence of past-year criminal victimization in the US population was $4.1 \%$, which is greater than the NCVS estimates but somewhat lower than those from the ICARIS-2. Demographically, findings indicated that the prevalence of criminal victimization was greater among persons reporting lower levels of income, who were separated or divorced, and residing in urban areas. However, we found no significant relationship between victimization and education, which is correlated with income. This finding may reflect that income itself is a stronger factor in its association with heightened exposure to risk of experiencing a criminal victimization rather than education per se. Further, among those engaging in various forms of antisocial behavior, there was a uniform pattern of increased odds of experiencing a criminal victimization.

Thus, the present study provides solid evidence of the heightened level of risk experienced by different forms of antisocial behavior. The hypothesis that alcohol, marijuana, cocaine, stimulants, opioids, and heroin abuse/dependence would significantly increase the likelihood of experiencing a criminal victimization even while controlling for aforementioned mental health and psychiatric diagnoses and demographic variables was partially supported. Marijuana, stimulants and heroin use disorders, although elevated, were not significantly associated with criminal victimization. The strongest effects were found for adults with cocaine use disorder who were nearly four times more likely to be victimized than persons without such disorders, 
TABLE 3. Psychiatric comorbidities of adults with and without a past 12 -month criminal victimization

\begin{tabular}{|c|c|c|c|}
\hline Comorbid psychiatric disorder & Nonvictims $(n=40,237) \%(95 \% \mathrm{CI})$ & Victims $(n=1,779) \%(95 \% \mathrm{CI})$ & Adjusted ORs OR (95\% CI) \\
\hline \multicolumn{4}{|l|}{ Mood disorders } \\
\hline Major depressive disorder & $9.58(9.10-10.07)$ & $8.50(7.30-9.87)$ & $1.27(1.01-1.60)$ \\
\hline Mania/hypomania & $2.77(2.56-3.00)$ & $5.51(4.03-7.49)$ & $1.13(0.83-1.27)$ \\
\hline Dysthymia & $2.46(2.26-2.68)$ & $4.06(3.74-4.40)$ & $1.32(0.93-1.86)$ \\
\hline \multicolumn{4}{|l|}{ Anxiety disorders } \\
\hline Panic disorder & $2.51(2.30-2.74)$ & $2.46(1.45-4.13)$ & $1.42(1.01-1.99)$ \\
\hline Social phobia & $2.27(2.05-2.51)$ & $2.84(1.72-4.64)$ & $1.06(0.73-1.54)$ \\
\hline Specific phobia & $2.33(2.12-2.55)$ & $2.05(1.25-3.36)$ & $1.20(0.97-1.48)$ \\
\hline Generalized anxiety disorder & $2.09(1.89-2.32)$ & $3.71(2.35-5.81)$ & $1.10(0.81-1.48)$ \\
\hline \multicolumn{4}{|l|}{ Substance use disorders ${ }^{\mathrm{a}}$} \\
\hline Alcohol use disorder & $8.10(7.64-8.58)$ & $16.55(14.25-19.13)$ & $1.35(1.10-1.65)$ \\
\hline Nicotine dependence & $12.46(11.71-13.25)$ & $22.19(19.39-25.28)$ & $1.25(1.04-1.49)$ \\
\hline Marijuana use disorder & $1.32(1.17-1.49)$ & $4.88(3.76-6.30)$ & $1.29(0.91-1.83)$ \\
\hline Drug use disorders & & $0.28(0.42-1.62)$ & \\
\hline Stimulant & $0.14(0.10-0.19)$ & $0.52(0.74-2.98)$ & $1.91(0.63-5.76)$ \\
\hline Opioid & $0.04(0.24-0.40)$ & $0.15(0.09-0.82)$ & $2.56(1.18-5.56)$ \\
\hline Sedative & $0.02(0.12-0.21)$ & $0.15(0.14-0.82)$ & $0.50(0.10-2.57)$ \\
\hline Tranquilizer & $0.12(0.08-0.17)$ & $0.51(0.94-3.09)$ & $0.68(0.10-4.62)$ \\
\hline Cocaine & $0.03(0.16-0.27)$ & $0.29(0.51-1.72)$ & $3.84(1.83-8.08)$ \\
\hline Hallucinogens & $0.02(0.07-0.16)$ & $0.58(0.27-1.24)$ & $2.39(0.93-6.10)$ \\
\hline Heroin & $0.19(0.15-0.25)$ & & $1.70(0.66-4.35)$ \\
\hline Psychotic disorder & $0.42(0.35-0.51)$ & $1.32(0.78-2.23)$ & $1.78(0.90-3.52)$ \\
\hline \multicolumn{4}{|l|}{ Personality disorders } \\
\hline Avoidant & $2.30(2.09-2.54)$ & $5.98(94.16-8.54)$ & $0.74(0.51-1.06)$ \\
\hline Dependent & $0.44(0.35-0.55)$ & $2.17(1.17-3.97)$ & $1.47(0.83-2.62)$ \\
\hline Obsessive-compulsive & $7.81(7.36-8.29)$ & $15.44(12.81-18.49)$ & $1.16(0.95-1.43)$ \\
\hline Paranoid & $4.21(3.91-4.54)$ & $12.51(9.85-15.76)$ & $1.38(1.08-1.75)$ \\
\hline Schizoid & $3.02(2.78-3.29)$ & $8.28(6.30-10.81)$ & $1.26(0.96-1.67)$ \\
\hline Antisocial & $3.49(3.21-3.80)$ & $9.89(7.90-12.31)$ & $1.19(0.95-1.50)$ \\
\hline Histrionic & $1.77(1.60-1.95)$ & $4.96(3.53-6.93)$ & $0.95(0.72-1.27)$ \\
\hline Family history of antisocial behavior & $22.54(21.48-23.64)$ & $37.31(33.58-41.21)$ & $1.36(1.13-1.62)$ \\
\hline
\end{tabular}

$95 \% \mathrm{CI}=95 \%$ confidence interval; OR $=$ odds ratio adjusted for sociodemographic variables, lifetime psychiatric disorders, and a family history of antisocial behavior. OR values in bold are statistically significant.

${ }^{a}$ Substance use disorders reflect past 12 -month diagnosis.

whereas respondents with opioid disorders had approximately doubled risk for victimization compared with nondependent respondents.

That drugs of abuse may increase victimization is consistent with theories and findings from genetics, developmental psychology, and criminology that describe generalized disinhibitory neuroregulatory processes (e.g., diminished self-control) that increase risk exposure to violence (27-29). Research (30) suggests that the links between substance abuse and victimization are somewhat bidirectional in that drug use predicts later victimization and early victimization is associated with later illicit substance use. In addition, drug transactions often involve situations and persons that may pose environmental risks for victimization. These explanations are consistent with the psychopharmacologic and systemic components of Goldstein's tripartite framework (31).

Another mechanism placing persons at increased risk for victimization is derived from behavior genetics. Consistent behavior genetic research has implicated monoamine oxidase $\mathrm{A}$ in decreased regulation in prefrontal functioning among male subjects (32). Recent research, for example, has suggested that male subjects with low-activity monoamine oxidase A alleles were associated with gang membership but also weapon use while in a gang (33). Thus, genetic liability is one mechanism by which individuals are at increased risk for placing themselves in victimization situations. In addition, drug transactions often involve situations and persons that may pose environmental risks for victimization. Another set of factors to consider is that crime and victimization tends to co-occur, at least in most industrialized countries, in areas that experience relatively high levels of concentrated disadvantage (e.g., poverty, racial segregation, high unemployment).

Unraveling the conjunction of individual liability and structural factors will require a more "syndemic" approach that is beyond the scope of the present investigation. Given the complexity of the substance abuse and criminal victimization relationship, future research might beneficially employ an explicit syndemic biosocial framework in 
facilitating systematic study of the various components of this relationship.

\section{Limitations}

As with other studies, current study findings require interpretation within the context of several limitations. One limitation is the data are cross-sectional. As such, the findings cannot clarify the causal relations between experiencing a criminal victimization and identified correlates. However, findings do suggest that criminal victimization and substance abuse are intertwined. The prognostic relationship between victimization and substance use disorders and psychiatric disorders will require longitudinal study designs beginning earlier in the life course. Although the NESARC is a nationally representative sample, it is uncertain how the association between victimization and substance use disorders and psychiatric comorbidity would be similar or different if enriched correctional or clinical samples were employed. An additional important limitation is that the data on victimization were assessed by a single item and thus did not include important contextual, situational, and precipitating information that is important to understanding the nature of victimization episodes. Future studies on victimization and substance use disorders would benefit from including these natural history features in such assessments. Despite these limitations, findings from this study provide new epidemiologic insights from which additional hypotheses can be derived. As victimization costs are extensive, in-depth analyses in large representative data sets becomes a valuable source for guiding prevention and policy efforts.

\section{REFERENCES}

1. Klaus PA. Costs of Crime to Victims. Washington, DC: U.S. Department of Justice, Office of Justice Programs, Bureau of Justice Statistics; 1994.

2. Miller TR, Cohen MA, Wiersema B. Victim Costs and Consequences: A New Look. Washington, DC: U.S. Department of Justice, Office of Justice of Programs, National Institute of Justice; 1996.

3. Turner HA, Finkelhor D, Ormod R. The effect of lifetime victimization on the mental health of children and adolescents. Soc Sci Med. 2006;62:13-27.

4. Caspi A, McClay J, Moffitt TE, Mill J, Martin J, Craig IW, et al. Role of genotype in the cycle of violence in maltreated children. Science. 2002;297:851-854

5. Campbell JC. Health consequences of intimate partner violence. Lancet. 2002;359:1331-1336.

6. Kilpatrick DG, Acierno R. Mental health needs of crime victims: Epidemiology and outcomes. J Traumatic Stress. 2003;16:119-132.

7. Simon TR, Kresnow M, Bossarte RM. Self-reports of violent victimization among U.S. adults. Violence Victims. 2008;23:711-726.

8. Rand MR. Criminal Victimization, 2007. Washington, DC: US Department of Justice, Office of Justice Programs, Bureau of Justice Statistics; 2008.

9. Pandiani JA, Banks SM, Carroll BB, Schlueter MR. Crime victims and criminal offenders among adults with serious mental illness. Psychiatric Services. 2007;58:1483-1485.
10. Teplin LA, McClelland GM, Abram KM, Weiner DA. Crime victimization in adults with severe mental illness: Comparison with the National Crime Victimization Survey. Arch Gen Psychiatry. 2005;62:911-921.

11. Maniglio R. Severe mental illness and criminal victimization: A systematic review. Acta Psychiatr Scand. 2009;119:180-191.

12. Choe JY, Teplin LA, Abram KM. Perpetration of violence, violent victimization, and severe mental illness: Balancing public health concerns. Psychiatric Services. 2008;59:153-164.

13. Lam JA, Rosenheck R. The effect of victimization on clinical outcomes of homeless persons with severe mental illness. Psychiatric Services. 1998;49:678-683.

14. Buss TF, Abdu JR, Walker JR. Alcohol, drugs, and urban violence in a small city trauma center. J Substance Abuse Treatment. 1995;12:75-83.

15. Flannery DJ, Singer MI, van Dulmen M, Kretschmar JM, Belliston LM. Exposure to violence, mental health, and violent behavior. In: Flannery DJ, Vazsonyi AT, Waldman ID, eds. The Cambridge Handbook of Violent Behavior and Aggression. New York: Cambridge University Press; 2007:306-321.

16. Macmillan R. Violence and the life course: The consequences of victimization for personal and social development. Ann Rev Sociol. 2001;27:122 .

17. Menard S. Short- and Long-Term Consequences of Adolescent Victimization. Washington, DC: US Department of Justice, Office of Justice Programs, Office of Juvenile Justice and Delinquency Prevention; 2002.

18. Ruback RB, Thompson MP. Social and psychological consequences of violent victimization. Thousand Oaks, CA: Sage; 2001.

19. Ramos-Lira L, Gonzalez-Forteza C, Wagner FA. Violent victimization and drug involvement among Mexican middle school students. Addiction. 2006;101:850-856.

20. Sells DJ, Rowe M, Fisk D, Davidson L. Violent victimization of persons with co-occurring psychiatric and substance use disorders. Psychiatric Services. 2003;54:1253-1257.

21. Grant BF, Dawson DA, Stinson FS, Chou PS, Kay W, Pickering R. The Alcohol Use Disorder and Associated Disabilities Interview Schedule-IV (AUDADIS-IV): Reliability of alcohol consumption, tobacco use, family history of depression and psychiatric diagnostic modules in a general population sample. Drug Alcohol Dependence. 2003;71:7-16.

22. Grant BF, Harford T, Dawson DA, Chou PS, Pickering RP. The Alcohol Use Disorder and Associated Disabilities Interview schedule (AUDADIS): Reliability of alcohol and drug modules in a general population sample. Drug Alcohol Dependence. 1995;39:37-44.

23. Hasin D, Carpenter KM, McCloud S, Smith M, Grant BF. The alcohol use disorders and associated disabilities interview schedule (AUDADIS): Reliability of alcohol and drug modules in a clinical sample. Drug Alcohol Dependence. 1997;44:133-141.

24. Grant BF, Stinson FS, Hasin DS, Dawson DA, Chou SP, Ruan WJ, et al. Co-occurrence of 12-month alcohol and drug use disorders and personality disorders in the United States: Results from the National Epidemiologic Survey on Alcohol and Related Conditions. Arch Gen Psychiatry. 2004;61:361-368.

25. Goldstein RB, Grant BF, Juan WJ, Smith SM, Saha TD. Antisocial personality disorder with childhood- vs. adolescence-onset conduct disorder: Results from the National Epidemiologic Survey on Alcohol and Related Conditions. J Nervous Ment Disord. 2006;194:667-675.

26. Research Triangle Institute. Software for Survey Data Analysis, SUDAAN. Version 9.0. Research triangle Park, NC: Research Triangle Institute; 2004.

27. Gottfredson MR, Hirschi T. A General Theory of Crime. Stanford, CA: Stanford University Press; 1990.

28. Moffitt TE. Adolescence-limited and life-course persistent antisocial behavior: A developmental taxonomy. Psychol Rev. 1993;100:674-701.

29. Vaughn MG, Beaver KM, DeLisi M, Perron BE, Schelbe L. Gene-environment interplay and the importance of self-control in predicting polydrug use and substance-related problems. Addict Behav. 2009;34:112-116. 
288 Vaughn et al.

30. Weiner MD, Sussman S, Sun P, Dent C. Explaining the link between violent perpetration, victimization, and drug use. Addict Behav. 2005;30:1261-1266.

31. Goldstein PJ. The drugs/violence nexus: A tripartite conceptual framework. J Drug Issues. 1985;15:493-506.
32. Meyer-Lindenberg A, Buckholtz JW, Kolachana B, Hariri AR, Pezawas L, Blasi G, et al. Neural mechanisms of genetic risk for impulsivity and violence in humans. Proc Natl Acad Sci.. 2007;338:6269-6274.

33. Beaver KM, DeLisi M, Vaughn MG. MAOA genotype is associated with gang membership and weapon use. Comprehensive Psychiatry. Epub May 5, 2009. 